\title{
HOW TO GET YOUR PAPER PUBLISHED
}

\author{
By the EdTror of the Journal
}

Few intending authors appreciate how the editors of medical and scientific periodicals work. The British Fournal of Psychiatry rejects about two-thirds of the papers submitted to it, and many of those accepted have to be partially re-written before they appear in print. Some explanation of the editorial reasons for this behaviour may be helpful. I, for one, am often saddened at having to refuse a contribution which is clearly the fruit of several people's hard work-a script which has been carefully written and retyped, diagrams beautifully drawn-and even more so when the study has involved many sessions of clinical interviews or many hours of laboratory effort. The author may be offering a little bit of his individual creative self, and in refusing his paper I am rejecting him. Of course there are plenty of journals in the world, and his piece may find a home elsewhere, but before turning it down we do often ask ourselves whether the observations and results it contains could be salvaged in some form for us.

A paper is a communication of facts and ideas, not of feeling. It is to help the reader's intellectual functions, not to generate emotions or provide mystical insights. It is philosophy rather than literature or art. Therefore, to do its work efficiently it must have clarity of thought, simple expression and a logical sequence in its presentation, and avoid repetition and fine phrases. A paper is about something, it has a subject and a point of view. That subject may be the answer to a question, and experiments or clinical observations may be made to find the answer, or it may be an hypothesis or the critique of an idea or a method. The summary of the paper should indicate what the essential subject and aim of the paper is, and whatever it is the author must make sure that he keeps to the point of his subject and does not wander off reporting irrelevant data or speculation.

The Editor views everything in three ways. $\mathrm{He}$ is part administrator, part reader's friend, and part poet. (I use the word in its old sense of a maker, a craftsman.) As administrator, he is concerned with costs : of paper, of printing, of postage, of advertising. A journal like ours, which goes out monthly to about 9,000 addresses all over the world, has continually to think of its weight or it finds itself slipping into a higher postal category and its postal bill leaps up. Printing tables of data is fiddly work for the compositor, a line diagram means the special work of the block-maker, a photograph may mean special paper as well as a block, and all these things add consider- ably to costs and must therefore be justified. In other words the Editor is conscious that his space is limited to about 80-100 pages monthly, and that he must not print large numbers of tables or allow the same information to be duplicated in table and figure. These are some basic constraints on selection. Therefore, the author who writes at great length, say over 30 pages of typescript excluding tables and references, is making his acceptance unlikely. So is the author who puts all his work into 20 or so tables of data.

The Editor approaches all contributions as a spokesman for the readership. Can one make out what the author's subject really is (titles, and even summaries, are often poor guides)? Can one follow the paper, or are parts of it difficult or incomprehensible? Do parts seem irrelevant? If it is not intelligible to the Editor it may not be to most readers. Does it seem to contain any new ideas or observations, or is it a re-writing of what might be found in any big textbook? Is its subject relevant to the readership? For example, we occasionally get papers in which chronic schizophrenics have served as the guinea-pigs for a comparison of liver function tests, shall we say. The interest lies in the bio-chemistry of these tests, it is an incidental that the test subjects were psychiatric, and therefore such a paper should go to a journal of clinical pathology. Of course, in making these assessments the Editor is helped by editorial colleagues, and a vast panel of specialists in different clinical and scientific fields.

Given that the paper has some novelty and some interest for us, the question remains how much?and that leads us back to the question of length. Space is limited, we want to give as many authors and subjects as possible a chance of expression, and some subjects are more important or novel or interesting than others. One subject may be worth a typescript of 20 pages, another only 4, a third should be a brief 'letter to the Editor', and so on. The Editor chooses these lengths on behalf of readers, but he only does so successfully if he pleases at least himself.

This is the Editor as poet, with his conception of what the foumal ought to be doing and how it ought to look. We are a journal for general psychiatry, and therefore must include epidemiology, biochemistry, child psychiatry, forensic work, analytical psychotherapy, etc. We must also give encouragement to neglected fields, and strike a balance among them all. We may publish occasional reviews of areas of knowledge, but we want to capture the first 
reports of new insights at home and abroad, particularly if they may affect practice. We want to reflect all aspects of the psychiatric life, particularly as it is experienced in Britain. We want to encourage authors who work under difficulties, those who manage to do research in provincial mental hospitals away from academic centres, or who work in countries of Africa and the East where psychiatry is not yet well developed. At the same time we try to adhere to certain standards.

The most important is the scientific attitude. We expect hypotheses to be based on observations, and to lead to further observations which can test their theoretical correctness. We want to know in sufficient depth how the observations were made, so that others can attempt to repeat them. We are not very interested in any ideas, however brilliant and appealing in themselves, which are not provided with some kind of factual base.

We are against an author producing many papers - presumably chiefly for personal professional reasons-where one would do. It is harder for readers to follow, bad for the subject and wasteful of space if a research is reported in a series of tiny dribbles instead of in one big paper; worse still if the author releases at three-monthly intervals a succession of papers reanalysing the data of the same experiment. Fragmentation is an unnecessary evil.

An editor lays down rules and guidelines, yet a part of his success lies in knowing when to ignore them. He must be flexible, open to new suggestions, and yet maintain a character. In sum, to increase your paper's chance of acceptance you need to make clear to yourself what your subject really is. You must choose an appropriate length and keep within it, and you must develop your account according to some logical scheme which the reader can grasp, and avoid irrelevance of data or ideas. Don't repeat the Introduction in the Discussion, and don't write a long Introduction if you can refer to a textbook or review article which says it all. Don't put all your data in, just what is necessary to make your points. Try your draft on a friend, not necessarily knowledgeable but candid, who will tell you about confusion and muddle, omissions and non-sequiturs. It is only too easy for the author who knows the material too well to forget to mention vital points or to become blind to what his script actually says.

Strive always for straightforwardness and clarity. The paper by Jane Smith on 'What does the subeditor do?' in the British Medical Journal (1978) i, 222 (28 January) is worth reading in this connection.

\section{THE SGRIBE'S COLUMN}

\section{Patient Found Missing}

Among the severe shortages currently afflicting psychiatric hospitals there is one which is particularly worrying and which, if not remedied, will bring the psychiatric services of this country to a full stop. The purpose of this communication is to suggest certain measures which may prove helpful.

The particular shortage in question is, of course, the rapidly dwindling numbers of acceptable inpatients. Different psychiatric units have different in-patient needs, and it is, for example, extremely difficult to find patients who will fit the requirements of certain acute psychiatric units in District General Hospitals, especially where these are associated with Professorial Units-but the problem is much more extensive than even this.

An example of the desperate straits which some psychiatric units have reached is provided by the increasing number of urban (and rural) guerrilla bands nowadays dispatched to search the cities and countryside for much-wanted patients. These small, often partially trained, teams of men and women carry nothing more lethal than syringes and longacting phenothiazines (a technique developed from the tranquillizing darts used in game reserves). Known as psychiatric community nurses, they have had quite spectacular successes in trapping and recovering patients at large in the community, either at home or even including those who have strayed too far from a local authority hostel. These dedicated groups act as undercover agents. Abandoning their nurses' uniforms, they dress in a wide variety of highly personalized mufti which, with appropriate hair styles, have enabled them to pass themselves off as harmless vagrants or research workers.

The work has not been without its dangers. Some groups of patients have organized themselves into 